IFN Working Paper No. 1065, 2015

\title{
Wind Power Volatility and the Impact on Failure Rates in the Nordic Electricity Market
}

Sara Fogelberg and Ewa Lazarczyk 


\title{
Wind power volatility and the impact on failure rates in the Nordic electricity market. ${ }^{1}$
}

\author{
Sara Fogelberga and Ewa Lazarczyk•
}

\begin{abstract}
Wind power generation of electricity has gained popular support because of its low environmental impact and because of its low costs relative to other renewable energy sources. However, concerns have been raised in the power sector that wind power generation will come with the price of increased damage to other power generators. Wind power generation is naturally volatile which requires other power sources to start up and shut down in accordance with weather conditions, which for instance coal or gas generators are not built to do. The previous literature has used simulations to show that the damage done and the associated costs can be substantial. We use a dataset containing all reported failures in the Scandinavian electricity market Nord Pool and data for Danish wind power generation. The analysis shows that for Denmark the short term costs associated with the volatility of wind power generation are non-significant. Effects are slightly more pronounced for Nord Pool, indicating that the other countries in Nord Pool bear some of the costs for Denmark's high share of wind power use.
\end{abstract}

Key words: intermittent electricity production, cycling costs, Nord Pool, UMMs, failures

JEL codes: Q4, L94

\footnotetext{
${ }^{1}$ We are grateful for comments from Mikael Priks, Richard Friberg, Thomas Tangerås and Manja Gärtner. This paper was written while both authors were employed at the Research Institute of Industrial Economics (IFN) within the program The Economics of Electricity Markets. The authors gratefully acknowledge financial support from Energiforsk and the Swedish Energy Agency. Sara Fogelberg furthermore received funding from Nordic Energy Research.

${ }^{\square}$ Stockholm University and IFN, e-mail: sara.fogelberg@ne.su.se

-Research Institute of Industrial Economics (IFN), e-mail: ewa.lazarczyk@ifn.se
} 


\section{Introduction}

Demand for renewable energy sources has increased due to environmental concerns. One of the most important options for meeting renewable energy targets has been wind power since wind power is clean and reasonably cost effective. However, since wind generation is volatile, wind power needs to be complemented with large amounts of reserve capacity, often provided through coal, gas, oil or hydro. When wind power ceases to provide electricity the reserve capacity is required to start up and reversely it needs to shut down when winds are sufficiently strong. The frequent start-ups and shut-downs put a strain on the reserve capacity generators which could potentially mean more frequent failures or increased needs for maintenance compared to when wind power is not part of the energy mix (Troy et al. 2010). This is important since failures and maintenance threaten supply security and increase prices for consumers. Theoretical literature and simulations have shown that wind power use can create costs that outweigh or net benefits ${ }^{2}$.

In this paper we empirically investigate how volatility in wind power use affects the failure rates of other power sources, and specifically sources used for reserve capacity. Denmark is part of Nord Pool, the largest European electricity market, and we estimate effects both for Denmark and for all of Nord Pool. A well-integrated electricity market with less congestion can balance the volatility of wind power production better (Holttinen, 2005). This is especially true for Denmark since neighboring countries in Nord Pool have substantial amounts of hydro power, which can be argued to be naturally more flexible than for instance coal and gas. For this reason we estimate separate effects for when Denmark experience congestion, and hence is import or export constrained, and when Denmark can freely export and import. We estimate both shortterm results, that can have a causal interpretation, and long-term results that are more descriptive in nature. The short-term results can have a causal interpretation because wind is naturally exogenous and due to minimal marginal cost of wind power production, wind power units are utilized whenever it is windy (von der Fehr, 2013).

In our analysis we use a unique dataset containing wind power utilization in Denmark and failures reported in Urgent Market Messages (UMMs) released at the Nordic electricity market Nord Pool for the years 2006-2012. Denmark has the largest share of wind power use in the

\footnotetext{
${ }^{2}$ For papers discussing costs of integrating wind power see for instance Georgilakis (2008) and Smith et al. (2004).
} 
world; in 201333.2 percent of the Danish electricity consumption was covered by wind, which makes results for Denmark especially interesting (GWEC, 2013). The results in this paper will have policy implications for other areas that are heavily investing in wind power generation, such as Texas and Spain.

The results show that there is no short-term effect of wind power volatility on production failures in Denmark and that the effects for Nord Pool are marginal. Failure rates do not seem to be affected by whether there is congestion or not. Descriptive regressions aimed to capture a more long term effect of cycling (turning units on and off) on the power generation units show a weak significant impact of increased wind power production. The small effects could, however, be due to increased market integration with Sweden and Norway, as a larger market could enable better balancing especially with the use of hydro generation (Mauritzen, 2013). It is also possible that increased damage to units due to cycling was expected and hence investment in maintenance increased in our sample over time. Our results provide evidence that in Nord Pool inclusion of wind power in the market mix has only a small, positive effect on the number of failures and associated costs in the short run. As such, it contributes by revealing new evidence in support of wind power.

The previous literature has primarily analyzed expected costs associated with including wind power generation in electricity production mix. Kumar et al. (2012) and Georgilakis et al. (2008) show that cycling associated with the operation of units generating electricity at varying load levels puts pressure on the operating equipment resulting in higher plant operations and maintenance expenditures. Georgilakis et al. (2008) show that already at the 10 percent level of wind power penetration the economic cost of the operation of power system will increase.

Lefton and Besuner (2001) estimate that operation and maintenance costs for a start and shut down cycle of a gas unit range from $\$ 300$ to $\$ 80,000$. The costs represent the increased damage to plant equipment, lower fuel efficiencies and potentially shortened plant life. Hirth (2014) numerically analyzes the optimal share of wind and solar power, considering the natural volatility of those two power sources. He concludes that the optimal market share for wind power in Western Europe should be 20 percent, provided that the price is 50 Euros per MW. 
The paper is structured as follows: next section describes Danish wind power. Section 3 discusses consequences of increased wind production volatility and the effect they have on the power system. Sections 4 and 5 describe data and the empirical strategy. Results are discussed in section 6. The last section concludes.

\section{Danish wind power penetration and market conditions}

Development of wind power generation has been popular in Denmark since the 1970's when the oil crises led to economic difficulties. The impact of coal power on the climate and close-by environment together with a popular distrust in nuclear power paved way for efforts to expand wind power use (Goodard et al. 2004). Until 1973, 90 percent of the country's energy supply was based on imported oil. At the beginning of 1980's subsidies for the construction and operation of wind turbines, taxes imposed on oil and coal and additional tax incentives aimed at Danish families for generating power for their communities, increased interest in renewable power plans. Initial generous capital grants for up to 30 percent of the installation cost provided by the government were later reduced to 10 percent (IRENA, 2013).

The subsidies for the wind power were canceled in 1988 and in 1993 fixed-in tariff for wind power were introduced, to be replaced in 1999 by a system of tradable green certificates. Since 2003 an environmental premium was instead added to the market-clearing price for wind power generated electricity. The feed-in tariffs for turbines of all sizes were re-introduced in 2009. The initial drop of the feed-in tariff decreased willingness to invest in new turbines as can be seen in Figure 1 (IRENA, 2013). This explains why capacity and number of turbines have diverging time trends at the beginning of the 21 century. At the same time the Danish government ordered additional offshore wind power to be installed at five different locations.

Between 2004 and 2006, less than 40 MW of new wind capacity was added in Denmark. Local opposition to proposed wind projects grew and became an increasingly important political force. Most of the increase in Danish wind power capacity in the years after 2005 was due to the construction of large offshore wind farms. Denmark is the world-leading producer of commercial wind power mills and the domestic use of wind power has increased rapidly up until present numbers (DEA, 2009). 


\section{Figure 1. Development of Danish wind power use}

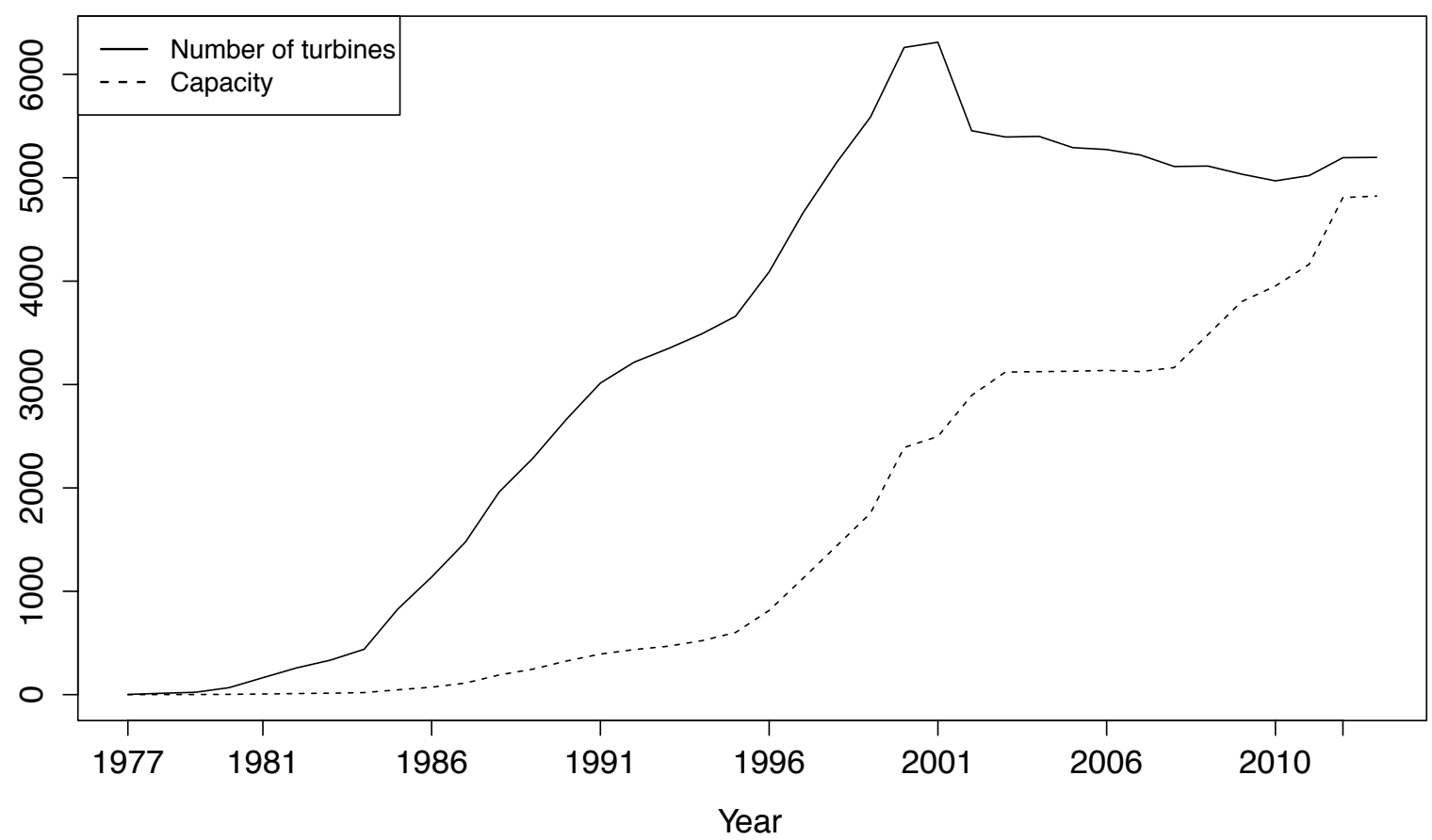

Note: This figure shows the number of turbines and the amount of installed wind capacity in Denmark over time. The data source is the Danish energy agency. ${ }^{3}$ The capacity is measured in MW.

Since 2000 Denmark has been part of the integrated Nordic energy market Nord Pool. Transmission at the present allows for exporting or importing up to 60 percent of production capacity. Despite a relatively large transmission capacity, congestion between countries is still common. Theoretically there is a joint market clearing spot price on Nord Pool but due to congestion there are different price zones where Denmark has two, one for west Denmark and one for east. While Denmark's electricity production mix is dominated by wind and coal, hydro and nuclear dominate in the countries north of Denmark. Norway produces electricity using predominantly hydro and Sweden's share of hydro is approximately 45 percent (IEA, Sweden,

\footnotetext{
${ }^{3}$ http://www.ens.dk/info/tal-kort/statistik-noegletal/oversigt-energisektoren/stamdataregister-vindmoller)
} 
2013). Today about 30 percent of the electricity consumed in Denmark comes from wind power and the number is projected to increase to 50 percent by 2020 (GWEC, 2013).

\section{Consequences of wind production volatility}

Rising amounts of wind power entering the electricity grids make the operation of the power system systematically more complex as variations in the net load (load minus wind) increase. Wind is an intermittent energy source and the fluctuations in output have to be offset to maintain the system in balance (the supply needs to equal the demand in every instance). Greater operational flexibility of the incumbent generators is necessary to balance the fluctuating wind.

Baseload technologies such as coal, oil and nuclear are built to withstand constant stress from being used consistently at full production. The stress involved with a constant high production is referred to in technical literature as creep conditions (EPRI, 2001). Fluctuating stresses caused by temperature and pressure changes is commonly called fatigue. Fatigue typically happens when units start up and shut off production, which in turn is called cycling. When units built to withstand creep conditions are cycled, creep fatigue results which in turn leads to damages such as cracking and mechanical failures (Lefton et al. 1997). "Thermal shock, metal fatigue, corrosion, erosion and heat decay are common damage mechanisms that result from cycling operation" (Troy et al. 2010).

All conventional units will be impacted to some extend by wind integration, mostly units are designed with minimal operational flexibility and thus, cycling will result in increased deterioration of various components leading to more frequent forced outages (Ford et al. 2009). However, the severity of plant cycling will depend not only on the generation mix but also on the availability of interconnection, which can potentially compensate the imbalances from wind power via exports/imports (Troy et al. 2010). Consequences of wind volatility will affect not only Denmark itself but the whole Nord Pool as the Nordic market is well integrated. It is possible that problems with creep fatigue in Denmark have actually decreased over time as Norway and Sweden have substantial amounts of hydro power to balance the Danish wind power if there is enough transmission capacity. It also possible that Danish wind production is "exporting" its cycling problems to the rest of Nord Pool. 


\section{Data}

The wind production data used in this paper comes from Energinet, the Danish Transmission System Operator (TSO). Data for failures come from a collection of Nord Pool's Urgent Market Messages (UMMs). The dataset is composed of messages informing about all planned and unplanned outages exceeding 100MW and lasting for more than $60 \mathrm{~min}$ that were recorded in the Nord Pool area. Based on the information extracted from the UMMs we are able to identify the area that is potentially going to be most affected by the event that the message is informing about. The affected area is identified by the issuer of the message. Failure data is available for generators using different fuel types. We have access to hourly data for the years 2006-2012.

In Tables 1 and 2 we report weekly data describing Danish wind production and the number of failures registered by different types of units generating electricity in Denmark and in the whole of Nord Pool. The average weekly variation in Danish wind power amounts to over $500 \mathrm{MW}$.

In Denmark, during the analyzed period, on average 2.67 failures weekly have been registered; with the most frequent failures observed in coal-fueled units. Gas and oil-fueled units were relatively less prone to damages with only 0.36 registered failures on average per week. The mean number of failures registered in the entire Nord Pool over a week is 10.43; with hydro failures reaching the number of 4.3 over a week. On average 1.5 failures per week encountered by TSOs were registered over the analyzed period. 
Table 1. Summary statistics describing Danish wind production and the number of failures registered as affecting Denmark, weekly data.

\begin{tabular}{lcccc}
\hline & Mean & Standard dev. & Min & Max \\
\hline & & & & \\
Danish wind production & 547.67 & 233.43 & 36.5 & 1168.11 \\
Failure & 2.67 & 2.3 & 0 & 13 \\
Failure wind & 0.02 & 0.16 & 0 & 2 \\
Failure coal & 2.17 & 2.04 & 0 & 10 \\
Failure gas & 0.36 & 0.71 & 0 & 7 \\
Failure oil & 0.36 & 0.8 & 0 & 5 \\
Failure TSO & 0.34 & 0.7 & 0 & \\
\end{tabular}

Note: This table presents summary statistics for Danish weekly wind production and the weekly number of new production failures registered as affecting Denmark between the $1^{\text {st }}$ of January 2006 and the $31^{\text {st }}$ of December 2012. Wind production is measured as the standard deviation of wind production (in MW) over a week.

Table 2. Summary statistics describing the number of failures registered in Nord Pool, weekly data

\begin{tabular}{lcccc}
\hline & Mean & Standard dev. & Min & Max \\
\hline Failure & 10.43 & 6.7 & 0 & 35 \\
Failure coal & 3.3 & 2.62 & 0 & 17 \\
Failure gas & 0.81 & 1.25 & 0 & 8 \\
Failure oil & 0.98 & 1.59 & 0 & 9 \\
Failure biofuel & 0.04 & 0.26 & 0 & 5 \\
Failure nuclear & 0.68 & 0.91 & 0 & 18 \\
Failure hydro & 4.30 & 3.5 & 0 & 17 \\
Failure TSO & 1.5 & 1.78 & 0 & 2 \\
\hline
\end{tabular}

Note: This table presents summary weekly statistics of the number of new production failures registered in the Nord Pool between the $1^{\text {st }}$ of January 2006 and the $31^{\text {st }}$ of December 2012, weekly number of new production failures registered by power units powered by different energy sources and the weekly number of new production failures registered by the Nordic Transmission System Operators (TSOs). 


\section{Econometric strategy}

In this paper we aim to measure how volatility of wind power generation affects the risk of failures being reported by other power generation sources, such as oil, coal, gas, hydro and nuclear. We estimate the effects both for failures affecting Denmark (hence to a higher degree domestic production sources) and all failures reported on Nord Pool. We estimate the effects for all fuel types.

The regressions have the following structure:

$$
Y_{t}=\alpha+\beta X_{t}+\varepsilon_{t}
$$

where $Y_{t}$ is the $\log$ of the sum of failures on a particular week $t . X_{t}$ is the $\log$ of the standard deviation in wind production on a particular week t. $\beta$ is the coefficient of interest, $\alpha$ is the intercept and $\varepsilon$ is the error term. Observations used for calculating this standard deviation are on an hourly basis. Failures are also reported on an hourly basis and they are aggregated to weekly numbers.

To capture whether market integration and congestion matter for failure rates we also estimate:

$$
Y_{t}=\alpha+\beta_{1} X_{t}+\beta_{2} I C_{t}+\beta_{3} E C_{t}+\beta_{4} X_{t} I C_{t}+\beta_{5} X_{t} E C_{t}+\varepsilon_{t}
$$

where $Y_{t}$ is the $\log$ of the sum of failures on a particular week $t . X_{t}$ is the $\log$ of the standard deviation in wind production on a particular week t. ICt is a variable for import congestion, defined as the sum of hours over a week where prices in Denmark were higher than prices in neighboring zones. ECt is a variable for export congestion defined as the sum of hours over a week where prices in neighboring zones were higher than in Denmark. $\mathrm{X}_{t} \mathrm{IC}_{t}$ and $\mathrm{X}_{t} \mathrm{EC}_{t}$ are interaction variables for wind volatility and import/export congestion respectively.

Because of negligible marginal cost of production, wind power is generated whenever it is windy, even when prices are very low (Mauritzen, 2013). Wind in itself is strictly exogenous, which enables us to interpret the estimates as causal effects of wind power volatility. As Mauritzen (2013) points out, however, there may be two cases in which wind generation is dependent not only on wind. The first case is that the system operator may order some wind generation off the market to balance supply and demand. On rare occasions in Denmark the price 
goes down to zero or become negative, which would imply that there is a potential balancing problem in the market. The impact of this on the results should be marginal however. We checked how often prices drop to zero or below zero in the intra-day market for the years 20102012. Out of 404,744 trades in that market only 0.05 percent were negative or zero.

A second plausible problem is that a producer that owns several generation technologies might try to influence prices by withholding wind power generation. However, wind power would, given its low marginal production cost, be the least likely type of generation to withhold. Given good public information about installed capacity and strength of winds it would also constitute a rather transparent type of market power abuse.

In the main specifications of this paper we cannot consider that wind power volatility may have a more long-term effect on failure rates of other electricity utilities. Therefore, we also run regression describing the long-term relationship between failures for different utilities and use of wind power generation. We estimate the following model:

$$
Y_{t}=\alpha+\beta W_{t}+\varepsilon_{t}
$$

where $\mathrm{Y}_{\mathrm{t}}$ is the $\log$ of number of failures per week, $\mathrm{W}_{\mathrm{t}}$ is the $\log$ of wind production in MW per week, $\varepsilon$ is the error term and $\beta$ is the coefficient of interest. 


\section{Results}

As it can be seen in Table 3, we find no significant results of wind power volatility on the failure rates in Denmark, in the short run.

Table 3. Short term effects of wind volatility on failure rates in Denmark.

Log-log model corresponding to eq. (1).

\begin{tabular}{lccccc}
\hline & All failures & Gas & Oil & Coal & TSO \\
\hline Log of wind volatility & -0.045 & 0.025 & $0.099^{*}$ & -0.086 & 0.016 \\
& $(0.067)$ & $(0.044)$ & $(0.053)$ & $(0.069)$ & $(0.045)$ \\
& 364 & 364 & 364 & 364 & 364 \\
Observations & 0.001 & 0.001 & 0.011 & 0.004 & 0.000 \\
R-squared & & & & \\
& & &
\end{tabular}

We find positive significant effects of wind volatility on the number of failures registered in the entire Nord Pool. An increase in standard deviation of 1 percent results in 0.2 percent more failures. For gas and oil the corresponding effect is 0.14 and 0.4 percent respectively. There is a significant effect on hydro of 0.18 percent.

Table 4. Short term effects of wind volatility on failure rates in Nord Pool. Log-log model corresponding to eq. (1).

\begin{tabular}{lccccccc}
\hline & All failures & Gas & Oil & Coal & Hydro & Nuclear & TSO \\
\hline Log of wind volatility & $0.202^{* * *}$ & $0.143^{* *}$ & $0.399^{* * *}$ & -0.012 & $0.177^{* *}$ & 0.028 & 0.089 \\
& $(0.061)$ & $(0.064)$ & $(0.075)$ & $(0.063)$ & $(0.077)$ & $(0.056)$ & $(0.067)$ \\
Observations & 364 & 364 & 364 & 364 & 364 & 364 & 364 \\
R-squared & 0.030 & 0.013 & 0.079 & 0.000 & 0.016 & 0.001 & 0.004 \\
\hline
\end{tabular}

Note: Robust standard errors in parentheses; ${ }^{* * *} \mathrm{p}<0.01,{ }^{* *} \mathrm{p}<0.05,{ }^{*} \mathrm{p}<0.1$

To investigate the impact of market integration in Table 5 we include controls and interaction terms for import and export congestion. The results for Denmark are insignificant. 
Table 5. Short term effects of wind volatility on failure rates in Denmark. Log-log model corresponding to eq. (2).

\begin{tabular}{lccccc}
\hline & All failures & Gas & Oil & Coal & TSO \\
\hline & & & & & \\
Log of wind volatility & -0.043 & 0.018 & 0.064 & -0.079 & -0.049 \\
& $(0.084)$ & $(0.054)$ & $(0.067)$ & $(0.085)$ & $(0.054)$ \\
Import Congestion & 0.001 & 0.000 & -0.000 & 0.001 & -0.000 \\
& $(0.001)$ & $(0.000)$ & $(0.000)$ & $(0.001)$ & $(0.000)$ \\
Export Congestion & -0.001 & -0.001 & -0.001 & -0.001 & $-0.001^{*}$ \\
Wind*ImportCongestion & $(0.001)$ & $(0.001)$ & $(0.001)$ & $(0.001)$ & $(0.001)$ \\
& -0.000 & -0.000 & 0.000 & -0.000 & 0.000 \\
Wind*ExportCongestion & $(0.000)$ & $(0.000)$ & $(0.000)$ & $(0.000)$ & $(0.000)$ \\
& 0.000 & 0.000 & 0.000 & 0.000 & $0.000^{* *}$ \\
& $(0.000)$ & $(0.000)$ & $(0.000)$ & $(0.000)$ & $(0.000)$ \\
Observations & & & & & \\
R-squared & 364 & 364 & 364 & 364 & 364 \\
& 0.018 & 0.016 & 0.028 & 0.019 & 0.018 \\
\hline Note: Robust & & & & & \\
\hline
\end{tabular}

Note: Robust standard errors in parentheses; ${ }^{* * *} \mathrm{p}<0.01,{ }^{* *} \mathrm{p}<0.05,{ }^{*} \mathrm{p}<0.1$

Results for the entire Nord Pool are consistent with Table 4. An increase in standard deviation of 1 percent results in 0.21 percent more failures. For gas and oil the corresponding effect is 0.2 and 0.37 percent respectively. There is a significant effect on hydro of 0.19 percent. Import congestion has a significant effect on hydro failures, however we do not find any effects for the interaction terms.

Table 6. Short term effects of wind volatility on failure rates in Nord Pool. Log-log model corresponding to eq. (2).

\begin{tabular}{|c|c|c|c|c|c|c|c|}
\hline & All failures & Gas & Oil & Coal & Hydro & Nuclear & TSO \\
\hline Log of wind volatility & $\begin{array}{l}0.208 * * * \\
(0.072)\end{array}$ & $\begin{array}{l}0.203 * * \\
(0.081)\end{array}$ & $\begin{array}{l}0.367 * * * \\
(0.097)\end{array}$ & $\begin{array}{l}-0.005 \\
(0.079)\end{array}$ & $\begin{array}{r}0.187 * * \\
(0.092)\end{array}$ & $\begin{array}{l}-0.004 \\
(0.073)\end{array}$ & $\begin{array}{c}0.094 \\
(0.090)\end{array}$ \\
\hline Import Congestion & $\begin{array}{c}0.002 * * * \\
(0.001)\end{array}$ & $\begin{array}{c}0.001 \\
(0.001)\end{array}$ & $\begin{array}{c}0.001 \\
(0.001)\end{array}$ & $\begin{array}{c}0.000 \\
(0.001)\end{array}$ & $\begin{array}{c}0.002 * * * \\
(0.001)\end{array}$ & $\begin{array}{l}-0.000 \\
(0.001)\end{array}$ & $\begin{array}{c}0.001 \\
(0.001)\end{array}$ \\
\hline Export Congestion & $\begin{array}{l}-0.000 \\
(0.001)\end{array}$ & $\begin{array}{c}0.000 \\
(0.001)\end{array}$ & $\begin{array}{c}0.001 \\
(0.001)\end{array}$ & $\begin{array}{l}-0.000 \\
(0.001)\end{array}$ & $\begin{array}{c}-0.000 \\
(0.001)\end{array}$ & $\begin{array}{l}-0.000 \\
(0.001)\end{array}$ & $\begin{array}{l}-0.000 \\
(0.001)\end{array}$ \\
\hline Wind*ImportCongestion & $\begin{array}{l}-0.000 \\
(0.000)\end{array}$ & $\begin{array}{l}-0.000 \\
(0.000)\end{array}$ & $\begin{array}{c}0.000 \\
(0.000)\end{array}$ & $\begin{array}{l}-0.000 \\
(0.000)\end{array}$ & $\begin{array}{l}-0.000 \\
(0.000)\end{array}$ & $\begin{array}{c}0.000 \\
(0.000)\end{array}$ & $\begin{array}{l}-0.000 \\
(0.000)\end{array}$ \\
\hline Wind*ExportCongestion & $\begin{array}{c}0.000 \\
(0.000)\end{array}$ & $\begin{array}{l}-0.000 \\
(0.000)\end{array}$ & $\begin{array}{c}0.000 \\
(0.000)\end{array}$ & $\begin{array}{c}0.000 \\
(0.000)\end{array}$ & $\begin{array}{c}0.000 \\
(0.000)\end{array}$ & $\begin{array}{l}-0.000 \\
(0.000)\end{array}$ & $\begin{array}{c}0.000 \\
(0.000)\end{array}$ \\
\hline $\begin{array}{l}\text { Observations } \\
\text { R-squared }\end{array}$ & $\begin{array}{c}364 \\
0.101\end{array}$ & $\begin{array}{c}364 \\
0.022\end{array}$ & $\begin{array}{c}364 \\
0.110\end{array}$ & $\begin{array}{c}364 \\
0.003\end{array}$ & $\begin{array}{c}364 \\
0.113\end{array}$ & $\begin{array}{c}364 \\
0.006\end{array}$ & $\begin{array}{c}364 \\
0.016\end{array}$ \\
\hline
\end{tabular}

Note: Robust standard errors in parentheses; $* * * \mathrm{p}<0.01,{ }^{* *} \mathrm{p}<0.05,{ }^{*} \mathrm{p}<0.1$ 
The results for the Nord Pool without failures in Denmark presented in Table 7 are similar to results presented in Table 6 .

Table 7. Short term effects of wind volatility on failure rates in Nord Pool excluding Denmark. Log-log model corresponding to eq. (2).

\begin{tabular}{|c|c|c|c|c|c|}
\hline & All failures & Gas & Oil & Coal & TSO \\
\hline Wind volatility & $\begin{array}{c}0.286 * * * \\
(0.085)\end{array}$ & $\begin{array}{c}0.211 * * * \\
(0.072)\end{array}$ & $\begin{array}{c}0.351 * * * \\
(0.078)\end{array}$ & $\begin{array}{c}0.094 \\
(0.083)\end{array}$ & $\begin{array}{c}0.122 \\
(0.086)\end{array}$ \\
\hline Import Congestion & $\begin{array}{c}0.002 * * * \\
(0.001)\end{array}$ & $\begin{array}{c}0.001 \\
(0.001)\end{array}$ & $\begin{array}{c}0.001 \\
(0.001)\end{array}$ & $\begin{array}{l}-0.000 \\
(0.001)\end{array}$ & $\begin{array}{c}0.001 \\
(0.001)\end{array}$ \\
\hline Export Congestion & $\begin{array}{l}-0.000 \\
(0.001)\end{array}$ & $\begin{array}{c}0.001 * * \\
(0.001)\end{array}$ & $\begin{array}{c}0.001 \\
(0.001)\end{array}$ & $\begin{array}{c}0.001 \\
(0.001)\end{array}$ & $\begin{array}{c}0.000 \\
(0.001)\end{array}$ \\
\hline Wind*ImportCongestion & $\begin{array}{l}-0.000 \\
(0.000)\end{array}$ & $\begin{array}{l}-0.000 \\
(0.000)\end{array}$ & $\begin{array}{c}0.000 \\
(0.000)\end{array}$ & $\begin{array}{l}-0.000 \\
(0.000)\end{array}$ & $\begin{array}{l}-0.000 \\
(0.000)\end{array}$ \\
\hline Wind*ExportCongestion & $\begin{array}{c}0.000 \\
(0.000)\end{array}$ & $\begin{array}{l}-0.000^{*} \\
(0.000)\end{array}$ & $\begin{array}{c}0.000 \\
(0.000)\end{array}$ & $\begin{array}{l}-0.000 \\
(0.000)\end{array}$ & $\begin{array}{c}0.000 \\
(0.000)\end{array}$ \\
\hline Observations & 364 & 364 & 364 & 364 & 364 \\
\hline R-squared & 0.117 & 0.028 & 0.123 & 0.023 & 0.016 \\
\hline
\end{tabular}

Note: Robust standard errors in parentheses; ${ }^{* * *} \mathrm{p}<0.01,{ }^{* *} \mathrm{p}<0.05,{ }^{*} \mathrm{p}<0.1$

The results capturing the long-term correlation between wind volatility and failure rates are reported in Table 8 for Denmark and Table 9 for the entire Nord Pool.

Table 8. Long term effects of wind production on number of failures in Denmark. Log-log model corresponding to eq. (3).

\begin{tabular}{cccccc}
\hline & All failures & Gas & Oil & Coal & TSO \\
\hline Wind production & -0.017 & 0.006 & $0.067^{*}$ & -0.042 & 0.051 \\
& $(0.053)$ & $(0.034)$ & $(0.041)$ & $(0.055)$ & $(0.037)$ \\
Observations & 364 & 364 & 364 & 364 & 364 \\
R-squared & 0.000 & 0.000 & 0.008 & 0.002 & 0.005 \\
\hline
\end{tabular}

Note: Robust standard errors in parentheses; $* * * \mathrm{p}<0.01,{ }^{* *} \mathrm{p}<0.05,{ }^{*} \mathrm{p}<0.1$

The descriptive regressions for Denmark show that there is no significant relationship between wind production and failures except for oil fueled power plants. An increase of 1 percent in wind 
production is associated with 0.07 percent increase in number of oil failures, which is a very small effect.

The results for the entire Nord Pool are reported in Table 9 and show that for certain types of units there are some small significant effects of the wind production on the number of failures. A 1 percent increase in wind production is associated with a $0.16 \%$ increase in the overall number of production failures in Nord Pool. Oil production seems to be mostly affected with a 0.3 percent increase in the number of failures associated with a 1 percent increase in the wind power. Significant results are also observed for hydro fueled plants and for failures registered by TSOs with respectively a 0.12 percent and 0.13 percent increases in the number of failures.

Table 9. Long term effects of wind production on number of failures in Nord Pool. Log-log model corresponding to eq. (3).

\begin{tabular}{cccccccc}
\hline & All failures & Gas & Oil & Coal & Hydro & Nuclear & TSO \\
\hline \multirow{2}{*}{ Wind production } & $0.159^{* * *}$ & 0.081 & $0.296^{* * *}$ & 0.017 & $0.118^{* *}$ & 0.062 & $0.129^{* *}$ \\
& $(0.049)$ & $(0.050)$ & $(0.060)$ & $(0.050)$ & $(0.058)$ & $(0.045)$ & $(0.056)$ \\
Observations & 364 & 364 & 364 & 364 & 364 & 364 & 364 \\
R-squared & 0.029 & 0.007 & 0.068 & 0.000 & 0.011 & 0.005 & 0.015 \\
\hline
\end{tabular}

Note: Robust standard errors in parentheses; $* * * \mathrm{p}<0.01,{ }^{*} \mathrm{p}<0.05,{ }^{*} \mathrm{p}<0.1$

\section{Conclusion}

The results show that the impact of wind production volatility on failure rates in other power generators is modest. The short run results, i.e. results that capture how volatility within a particular week affects failure rates, can have a causal interpretation due to the fact that the wind production is exogenous. The long-term results, where we estimate the effect of wind power production in MW over time on the number of failures, are more descriptive and a lack of significant results can be due to different factors. For instance, it is possible that Denmark anticipated increased wear and tear of the conventional capacity and compensated for this with increased maintenance. The significant results that we find for Nord Pool excluding Denmark might confirm that Denmark has invested in the electricity sector to prevent damage related to 
increased amounts of wind power. The effects of higher volatility are then observed in the rest of Nord Pool instead.

\section{References}

DEA, 2009, Danish energy agency, Accessed on March 20th 2015 from http://www.ens.dk/sites/ens.dk/files/dokumenter/publikationer/downloads/wind_turbines_in_den mark.pdf

Denny, E., O’Malley, M., 2009, The impact of carbon prices on generation-cycling costs, Energy Policy 37, pp. $1204-1212$.

EPRI, 2001, Damage to power plants due to cycling, Accessed on March 20th 2015 from http://www.epri.com/abstracts/Pages/ProductAbstract.aspx?ProductId=000000000001001507

von der Fehr, N.H., 2013, Transparency in electricity markets, Economics of Energy \& Environmental Policy, 2, 2, September, pp. 87-105.

Ford, J., Fernandes, J., Shibli, A., 2009, Damage to power plant due to cyclic operation and guidelines for best practices, European Technology Development Limited, UK, Accessed on March 20th 2015 from http:/electrivation.com/ftp/CEATI\%20TGIG\%20Cycling\%20Damage\%20to\%20Fossil\%20Plan ts/CEATI\%20TGIG\%20Damage $\% 20$ to $\% 20$ Power\%20Plant $\% 20$ fue $\% 20$ to $\% 20$ cycling\%20operat ion.pdf

Georgilakis, P.S., 2008, Technical challenges associated with the integration of wind power into power systems, Renewable and Sustainable Energy Reviews 12, 852-863.

Goddard, R.D., Vestergaard, J., Brandstrup, L., 2004, A brief history of the wind turbine industries in Denmark and the United States, Academy of International Business (Southeast USA Chapter) Conference Proceedings, November, pp. $322-327$.

GWEC, 2013, Global wind report, Annual market update, Global Wind Energy Council, Accessed on March 20th 2015 from http://www.gwec.net/wp-content/uploads/2014/04/GWECGlobal-Wind-Report_9-April-2014.pdf

Hirth, L., 2015, The Optimal Share of Variable Renewables: How the Variability of Wind and Solar Power affects their Welfare-optimal Deployment, The Quarterly Journal of the IAEE's Energy Economics Education Foundation, Volume 36, Number 1.

Holttinen, H., 2005, Impact of hourly wind power variations on the system operation in the 
Nordic countries, Wind Energy, Vol. 8, 2, pp. 197 - 218.

IEA, 2013, Energy policies of IEA countries, Sweden, Review, Accessed on March 20th 2015 from http://www.iea.org/publications/freepublications/publication/Sweden2013_free.pdf

IRENA, 2013, International Renewable Energy Agency, 30 years of policies for wind energy: lessons from 12 wind energy markets - Denmark, Accessed on March 20th 2015 from http://www.irena.org/DocumentDownloads/Publications/IRENA_GWEC_WindReport_Denmar k.pdf

Lefton, S., Besuner, P., Grimsrund, G., 1997, Understanding what it really costs to cycle fossilfired units, Power, 141, 2, pp. 41-42.

Lefton, S.,Besuner,P.,2001, Powerplant cycling operations and unbundling their effect on plant heat rate, APTECH Technical Paper, TP134.

Mauritzen, J., 2013, Dead Battery? Wind Power, the Spot Market, and Hydro Power Interaction in the Nordic Electricity Market, The Energy Journal, Vol. 34, No. 1.

Perez-Arriaga, I., Batlle, C., 2012, Impacts of intermittent renewables on electricity generation system operation, Economics of Energy and Environmental Policy, Vol.1, No. 2.

Smith, J.C., DeMeo, E.A., Parsons, B., Milligan, M., 2004, Wind power impacts on electric power system operating costs: summary and perspective on work to date, National Renewable Energy Laboratory, NREL/CP-500-35946

Troy, N., Denny, E., O’Malley, M., 2010, Base-load cycling on a system with significant wind penetration, IEEE Transactions on power systems.

Troy, N., 2011, Generator cycling due to high penetrations of wind power, Doctoral Thesis, School of Electrical, Electronic and Communications Engineering, University College Dublin, Ireland. 